\title{
Adult Pilocytic Astrocytoma
}

National Cancer Institute

\section{Source}

National Cancer Institute. Adult Pilocytic Astrocytoma. NCI Thesaurus. Code C71016.

A pilocytic astrocytoma occurring in adults. 